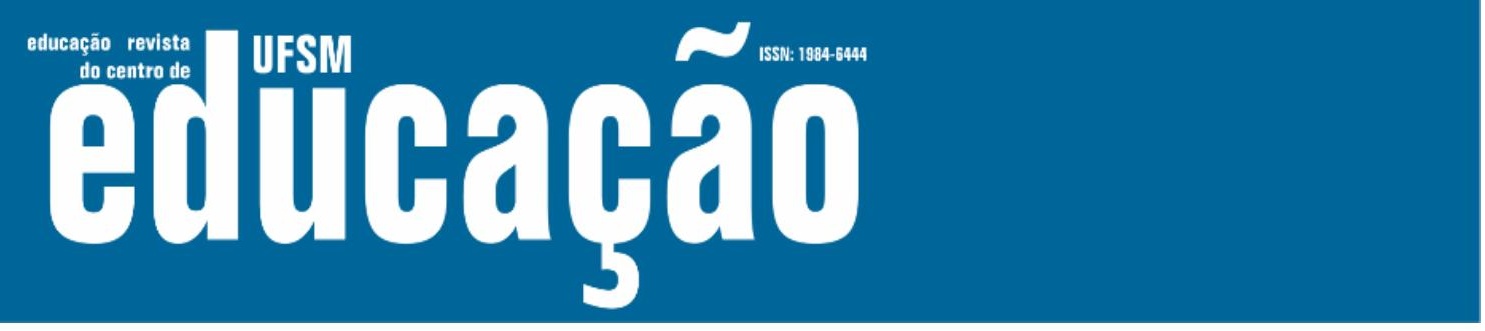

ISSN: 1984-6444 | http://dx.doi.org/10.5902/1984644436592

\title{
A inclusão na voz das professoras: emoções, sentidos e práticas no chão de escola sob a perspectiva histórico- cultural
}

Inclusion in teachers' voices: emotions, meanings and practices on the school floor from the historical-cultural perspective

Ana Carolina Lopes Venâncio

Professora doutora pela Universidade Federal do Paraná, Curitiba, Paraná, Brasil. anavenancio2704@gmail.com - https://orcid.org/0000-0001-6804-8711

Paula Maria Ferreira de Faria

Doutoranda na Universidade Federal do Paraná, Curitiba, Paraná, Brasil.

paula.pmff@gmail.com - https://orcid.org/0000-0001-9092-9988

Denise de Camargo

Professora doutora na Universidade Federal do Paraná e Universidade Tuiuti do Paraná, Curitiba, Paraná, Brasil.

denicamargo@gmail.com - https://orcid.org/0000-0002-8733-2969

Recebido em 26 de janeiro de 2019

Aprovado em 12 de novembro de 2019

Publicado em 24 de junho de 2020

\section{RESUMO}

Este artigo apresenta os achados de duas pesquisas qualitativas realizadas junto a professores dos anos iniciais do Ensino Fundamental, cujas temáticas abordam a inclusão escolar. O primeiro estudo objetivou investigar o potencial de um grupo de apoio entre professores no atendimento à diversidade e à inclusão, utilizando a metodologia proposta por Nicolini (2013). O segundo estudo investigou as emoções docentes em relação à inclusão escolar, utilizando entrevistas estruturadas, semiestruturadas e a produção de fotografias pelas professoras. Ambas as pesquisas seguem os referenciais da Teoria Histórico-Cultural e enfatizam a emoção como promotora das práticas de ensino e de aprendizagem. As professoras participantes relataram emoções como alegria, satisfação, frustração, solidão e desamparo frente ao processo inclusivo, indicando a necessidade da criação de redes que apoiem professores e gestores e informem as famílias e a comunidade escolar sobre o real contexto legal, prático e simbólico da inclusão. As participantes sugerem ainda o fortalecimento interno das equipes para maior alcance do ato de incluir, apontando a formação docente como chave para o sucesso desse movimento. Os resultados indicam que, apesar das vivências emocionais contraditórias acerca da inclusão, as professoras têm se dedicado a superar barreiras práticas e emocionais para aprimorar sua ação e atender a diversidade presente nas salas de aula. Reforçam também a 


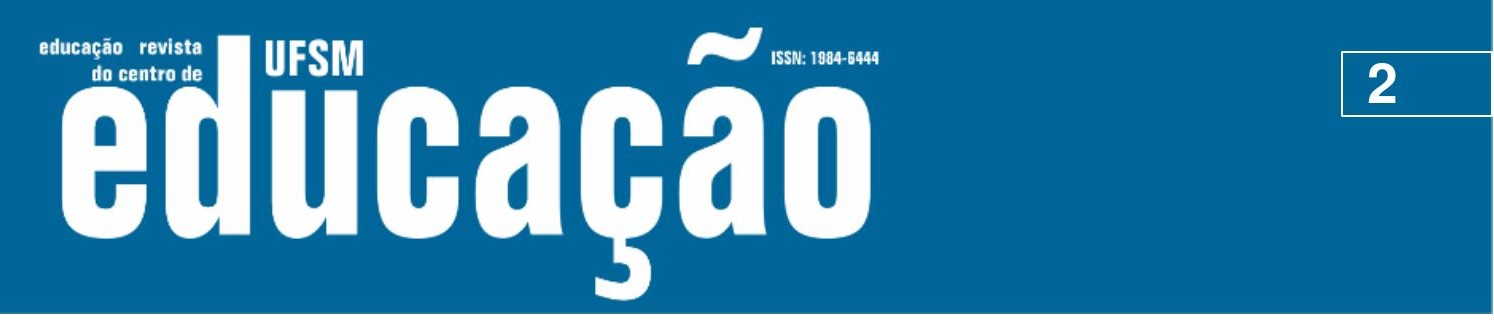

ISSN: 1984-6444 | http://dx.doi.org/10.5902/1984644436592

necessidade da formação de grupos de apoio que valorizem os aspectos cognitivos e emocionais de professores e alunos, buscando garantir a qualidade de trabalho e vida docente e a aprendizagem significativa de todos os estudantes.

Palavras-chave: Inclusão; Professores; Emoções; Teoria Histórico-Cultural.

\section{ABSTRACT}

This paper presents the findings of two qualitative studies conducted with teachers in the early years of elementary school, whose themes address school inclusion. The first study aimed to investigate the potential of a support group among teachers in meeting diversity and inclusion, using the methodology proposed by Nicolini (2013). The second study investigated teachers' emotions regarding school inclusion, using structured, semi-structured interviews and the production of photographs by teachers. Both researches follow the references of the Historical-Cultural Theory and emphasize the emotion as promoter of the teaching and learning practices. The participating teachers reported emotions such as joy, satisfaction, frustration, loneliness and helplessness in the inclusive process, indicating the need to create networks that support teachers and managers and inform families and the school community about the real legal, practical and symbolic context of the project. inclusion. The participants also suggest the internal strengthening of the teams to reach the inclusion act, pointing the teacher training as key to the success of this movement. The results indicate that, despite the contradictory emotional experiences about inclusion, teachers have been dedicated to overcoming practical and emotional barriers to improve their action and meet the diversity present in the classroom. They also reinforce the need for the formation of support groups that value the cognitive and emotional aspects of teachers and students, seeking to guarantee the quality of work and teaching life and the meaningful learning of all students.

Keywords: Inclusion; Teachers; Emotions; Historical-Cultural Theory.

\section{Introdução}

A educação contemporânea passa por uma crise. Embora historicamente tenha se constituído como campo em disputa, na dialética entre o direito, a igualdade e o direito à diferença (CURY, 2002), na atualidade os embatesse acirram frente ao novo cenário político e econômico. Devido ao fato de o direito à educação ainda não ter se consolidado mesmo sob a força de dispositivos legais, mantém-se a exclusão perpetuada pelos mecanismos de violência simbólica que a escola, enquanto campo de forças, exerce (BOURDIEU; PASSERON, 2013, 2014). 


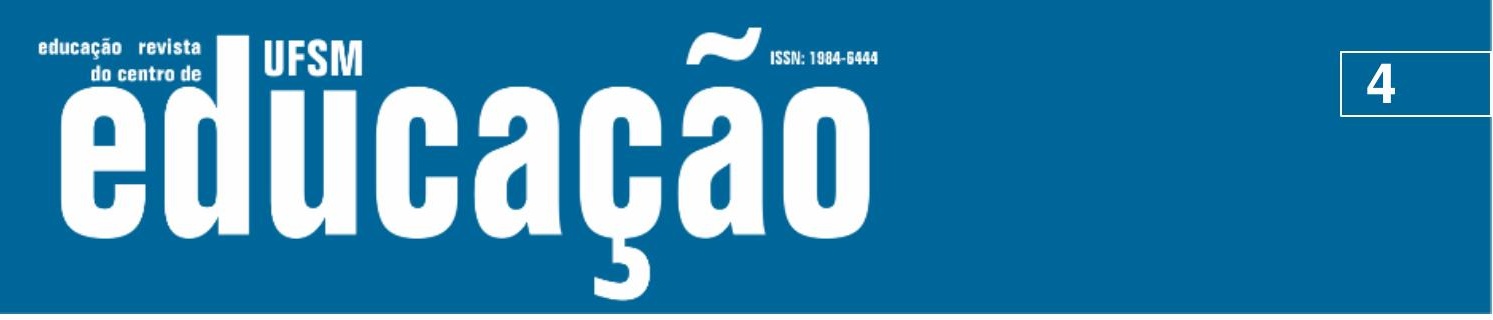

ISSN: 1984-6444 | http://dx.doi.org/10.5902/1984644436592

\section{Contextualização das pesquisas de campo: a inclusão escolar na voz das professoras}

A pesquisa "Grupos de Apoio Entre Professores e a Inclusão: uma reflexão sobre a reinvenção das práticas de docência a partir da ênfase no ensino colaborativo"4 investigou a ação de um Grupo de Apoio Entre Professores (GAEP) como estratégia de apoio para a adequação da prática docente no atendimento à diversidade. O campo de pesquisa foi uma escola pública da Rede Municipal de Ensino de Curitiba. A investigação levantou dados em relação às definições de inclusão, às representações das diferenças e seus impactos no cotidiano escolar, mapeou dificuldades e facilidades do processo inclusivo e revelou as emoções como dimensões que incitam e/ou paralisam os professores no exercício de sua profissão. Para análise das práticas, utilizou-se a proposta de Nicolini (2013). O autor apresenta uma metodologia que privilegia um movimento em três fases: zoom interno, para descrição densa da prática em estudo; zoom de fora, para percepção das suas conexões e inter-relações internas; e zoom interativo, visando compreender, interpretar e analisar as associações e maneiras socialmente convencionadas de sustentar as práticas em seu contexto e história.

Após a definição das pautas e do modelo de funcionamento do GAEP pelas professoras participantes, foi adotado o documento "Index para a inclusão: desenvolvendo a aprendizagem e a inclusão nas escolas" (BOOTH; AINSCOW, 2011) para subsidiar a avaliação corrente das ações do Grupo no movimento de ressignificação e reformulação das práticas em uso. A adoção desse material justificase pelo seu enfoque teórico-prático, voltado ao fortalecimento interno das equipes escolares, tendo em vista recursos humanos e materiais disponíveis na comunidade escolar. Para analisar como ocorria o processo de flexibilização curricular, entendida como balizadora da singularização das propostas pedagógicas que viabilizam a inclusão escolar, foram escolhidos três indicadores para análise das mudanças empreendidas nas práticas de docência: currículo, metodologia e avaliação.

A pesquisa "As emoções do professor frente à inclusão escolar" 5 buscou compreender as emoções do professor em relação ao processo de educação inclusiva 


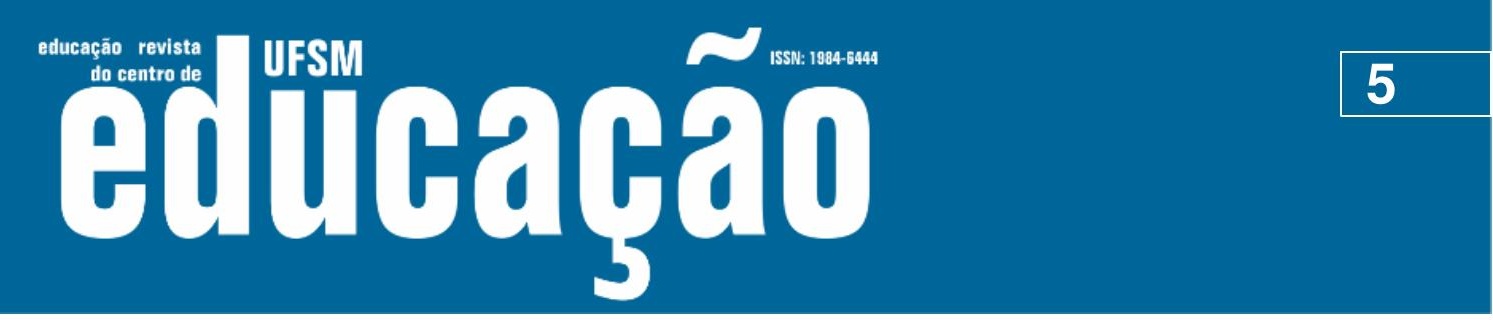

ISSN: 1984-6444 | http://dx.doi.org/10.5902/1984644436592

e ao estudante em processo de inclusão. Trata-se de um estudo qualitativo de caráter exploratório e interpretativo, fundamentado nos princípios da Teoria Histórico-Cultural, segundo a qual a subjetividade é uma produção humana que só pode ser significada a partir das experiências pessoais do sujeito, marcadas pelas condições de sua cultura em determinado contexto histórico.

A pesquisa foi realizada junto a três professoras da Rede Municipal de Ensino de Curitiba e utilizou entrevistas estruturadas, semiestruturadas e a autofotografia as participantes foram instadas a registrar, por meio fotográfico, suas emoções em relação ao processo de inclusão escolar e aos seus alunos. Todos os dados foram compreendidos sob os referenciais da Análise de Conteúdo (BARDIN, 2011). A autofotografia foi utilizada como um processo de pesquisa centrado no sujeito que permite acessar aspectos subjetivos por meio da interpretação relatada pelo próprio fotógrafo - pois cada imagem só pode ser compreendida a partir dos elementos que a contextualizam no contexto específico de sua produção (NEILVA-SILVA; KOLLER, 2002). Dessa forma, a fotografia revela formas particulares de subjetivação e constitui um instrumento mediador das emoções, através do qual cada professora pode construir e expressar significados e sentidos atribuídos ao processo de inclusão.

Ambas as pesquisas evidenciam o protagonismo das professoras, reforçando o trabalho docente como prática histórica e culturalmente situada cuja ação promove (ou dificulta) o desenvolvimento do processo de ensino-aprendizagem sob a perspectiva inclusiva.

\section{A voz do grupo: contribuições do GAEP à inclusão escolar}

A responsabilidade pela inclusão escolar tem recaído, na percepção das professoras participantes do GAEP, sobre as figuras do professor e do estudante; as redes de apoio existentes direcionam-se somente aos discentes, ainda sem atender a todos os que dela necessitam, devido à precariedade de condições de produção do ensino que caracteriza a escola pública brasileira. Essa situação revela a aparente dependência das equipes das escolas regulares em relação às professoras/pedagogas que atuam na modalidade de Educação Especial, 


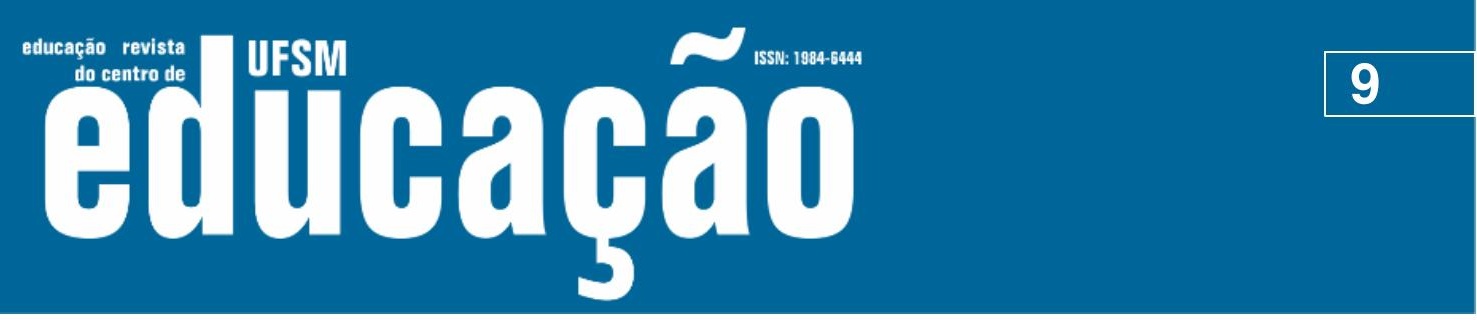

ISSN: 1984-6444 | http://dx.doi.org/10.5902/1984644436592

[...] redefinir o conceito de $\mathrm{AEE}$, não o restringindo ao atendimento complementar ou suplementar, de tamanho único para todos, mas ampliar, para englobar processos de escolarização em classe comum, com apoios centrados nesse próprio contexto (como por exemplo, co-ensino, consultoria colaborativa, tutoria de pares, ensino itinerante, auxiliares ou para profissionais, etc.), ou combinando com apoios extras a sala de aula (como por exemplo, em salas de recursos ou classes especiais), ou ainda em escolas especiais, em ensino domiciliar e em ensino hospitalar. (MENDES; MATURANA, 2016, s/p).

Além da redefinição do conceito de AEE, as participantes do GAEP defendem a superação do aspecto remediativo que caracteriza as políticas públicas que, além de não garantirem o atendimento universalizado à faixa de escolaridade obrigatória de 4 a 17 anos, ainda não preveem a possibilidade de intervenção precoce, o que torna ainda mais difícil uma inclusão posterior. Expõem, dessa forma, a urgência em construir um plano de trabalho de inclusão desde a Educação Infantil até o Ensino Superior, com apoio estruturado ao longo de todo o processo de escolarização estendido a toda comunidade escolar. Relatam, ainda, que os principais problemas da Educação Especial no Brasil são o acesso restrito e a pouca qualidade e denunciam que a lógica atual os acentua, ao invés de minimizá-los.

No GAEP foram, então, identificados diversos aspectos que promovem e também fragilizam a prática da docência. Ao analisar as estratégias utilizadas no decurso do magistério, as professoras participantes puderam perceber a riqueza de seus conhecimentos e experiências na construção de repertórios individuais, reconhecendo que ao compartilhá-los, novas estratégias são incorporadas à ação cotidiana enquanto equipe. No intercâmbio do Grupo ocorreu a ressignificação de práticas e conceitos que geram e permitem reconceitualizações no clima emocional da escola, promovendo um maior engajamento entre pessoas que trabalham em prol de metas comuns. O reconhecimento de emoções como insegurança, raiva, solidão e medo na estruturação de suas vivências diárias não as impediu de buscar novos caminhos diante dos desafios de sala de aula.

Em contrapartida, a empatia, a amorosidade e a dedicação se configuraram como emoções presentes no dia a dia das docentes e que contribuem na construção de uma alteridade diferenciada que as habilita a compreender mais do que julgar, as incitam ao acolhimento. Esse processo gerou desequilíbrio e retirou as professoras 


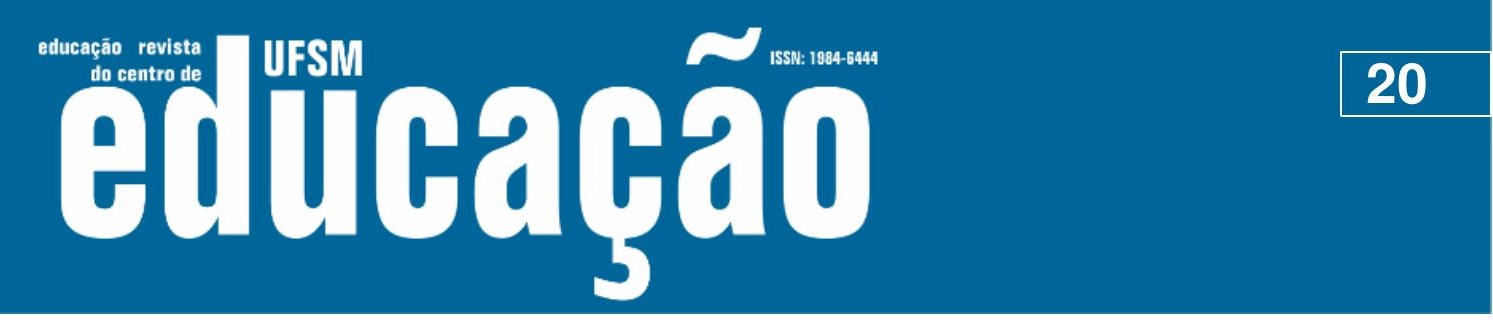

ISSN: 1984-6444 | http://dx.doi.org/10.5902/1984644436592

permitir e incitar o acolhimento de todos, independentemente de déficits ou necessidades singulares (KAFROUNI; PAN, 2001). Com vistas a esse fim, é fundamental refletir e repensar emoções e práticas, buscando coletivamente novas formas de ação que superem a atual condição dos sistemas de ensino e promovam a real inclusão - promotora de aprendizagem significativa para todos os estudantes.

\section{Referências}

AGUIAR, Wanda Maria Junqueira de. A escolha na orientação profissional: contribuições da psicologia sócio-histórica. Psicol. educ., São Paulo, n. 23, p. 11-25, $2^{\circ}$ sem. 2006.

ARROYO, Miguel Gonzalez. Ofício de mestre. 15. ed. 2. reimp. Petrópolis: Vozes, 2017.

BARDIN, L. Análise de conteúdo. Tradução de: RETO, L. A. L.; PINHEIRO, A. Lisboa: Edições 70, 2011. Título original: L'Analyse de Contenu.

BARROS, João Paulo Pereira; PAULA, Luana Rêgo Colares de; PASCUAL, Jesus Garcia; COLAÇO, Veriana de Fátima Rodrigues; XIMENES, Verônica Morais Ximenes. O conceito de "sentido" em Vygotsky: considerações epistemológicas e suas implicações para a investigação psicológica. Psicol. Soc., Belo Horizonte, v. 21, n. 2, p. 174-181, 2009.

BOOTH, Tony; AINSCOW, Mel. Index para a inclusão: desenvolvendo a aprendizagem e a participação nas escolas. 3. ed. Tradução de Mônica Pereira dos Santos e João Batista Esteves. Rio de Janeiro: LaPEADE, 2011.

BOURDIEU, Pierre; PASSERON, Jean-Claude. A reprodução: elementos para uma teoria do sistema de ensino. Tradução de Reynaldo Bairão. 6. ed. Petrópolis: Vozes, 2013.

BOURDIEU, Pierre; PASSERON, Jean-Claude. Os herdeiros: os estudantes e a cultura. Florianópolis: UFSC, 2014.

CAMARGO, Denise de. As emoções e a escola. Curitiba: Travessa dos Editores, 2004.

CAMARGO, Denise de; BULGACOV, Yára Lucia Mazziotti. Recuperação histórica do conceito de emoção em Vygotsky: contribuição para a tese da indissociabilidade da emoção na atividade humana. INFAD Revista de Psicología, Badajoz, n. 1, v. 1, p. 213-220, 2016.

CURY, Carlos Roberto Jamil. Direito à educação: direito à igualdade, direito à diferença. Cadernos de Pesquisa, São Paulo, n. 116, p. 245-262, jul. 2002. 


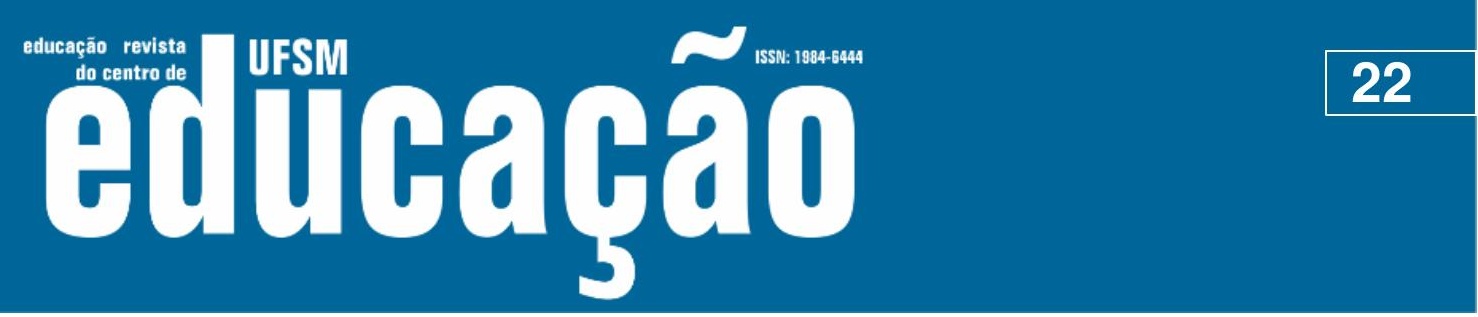

ISSN: 1984-6444 | http://dx.doi.org/10.5902/1984644436592

SOARES, Maria Tereza Perez. As emoções e os valores dos professores brasileiros. São Paulo: Fundação SM/OEI, 2007.

TASSONI, Elvira Cristina Martins; LEITE, Sérgio Antônio da Silva. Um estudo sobre emoções e sentimentos na aprendizagem escolar. Comunicações, Piracicaba, n. 18, v. 2, p. 79-91, jul./dez. 2011.

TOASSA, Gisele. Conceito de consciência em Vygotsky. Psicologia USP, São Paulo, v. 17, n. 2, p. 59-83, 2006.

TOASSA, Gisele. Emoções e vivências em Vygotsky: investigação para uma perspectiva histórico-cultural. 348f. Tese (Doutorado em Psicologia) - Instituto de Psicologia, Universidade de São Paulo, São Paulo, 2009.

UNESCO - ORGANIZAÇÃO DAS NAÇÕES UNIDAS PARA A EDUCAÇÃO, CIÊNCIA E CULTURA. Declaração de Salamanca sobre princípios, políticas e práticas na área das necessidades educativas especiais. Salamanca: UNESCO, 1994.

VENÂNCIO, Ana Carolina Lopes.Grupos de Apoio Entre Professores e a inclusão: uma reflexão sobre a reinvenção das práticas de docência a partir da ênfase no ensino colaborativo. 340f. Tese (Doutorado em Educação) - Setor de Educação, Universidade Federal do Paraná, Curitiba, 2017.

VYGOTSKY, Lev Semenovitch. Psicologia pedagógica. 2. ed. Tradução de Paulo Bezera. São Paulo: Martins Fontes, 2004. (Original publicado em 1924)

VYGOTSKY, Lev Semiónovic. Obras escogidas IV: paidología del adolescente; problemas de la psicología infantil. Madrid: Visor, 1996. (Original publicado em 19311933).

VYGOTSKY, Lev Semiónovic. Obras escogidas V:fundamentos de defectología. Madrid: Visor, 1997. (Original publicado em 1924-1934).

\section{Correspondência}

Ana Carolina Lopes Venâncio - Rua Wanda Wolf, 1660, ap. 1, bl. 1, CEP 82410 380, Curitiba, Paraná, Brasil.

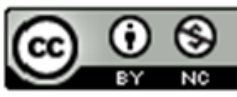

This work is licensed under a Creative Commons Attribution-NonCommercial 4.0 International (CC BY-NC 4.0) 


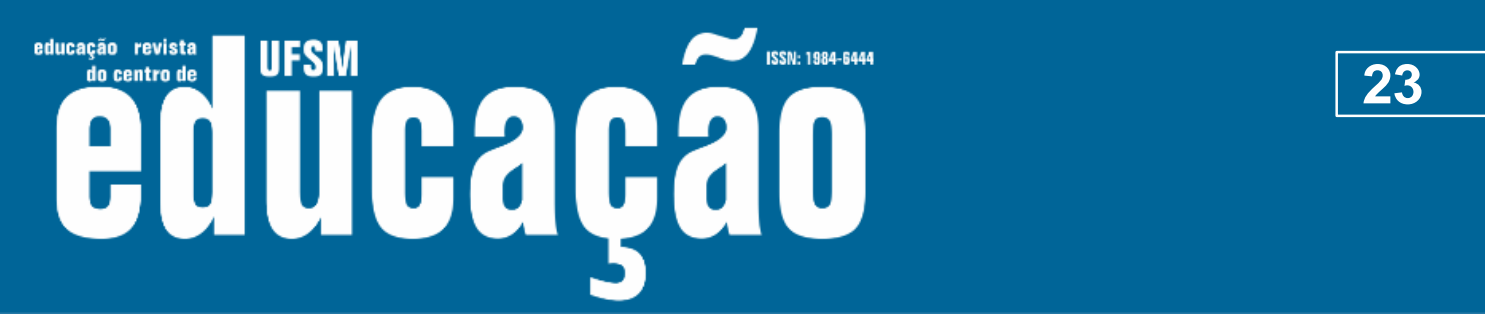

ISSN: 1984-6444 | http://dx.doi.org/10.5902/1984644436592

\section{Notas}

${ }^{1}$ Empregamos o termo "aluno" como sinônimo de "estudante" ou "educando", tal como é utilizado pelo Ministério da Educação em documentos que referenciam a educação inclusiva no âmbito nacional. Seguimos a norma culta da língua portuguesa, nos referindo aos gêneros masculino e feminino; leia-se, da mesma forma, o uso do termo "professor".

${ }^{2}$ As pesquisas foram realizadas no período entre 2014 e 2018.

${ }^{3}$ A pesquisa contou com o financiamento da Agência CAPES (bolsa de Mestrado).

${ }^{4}$ Pesquisa de Doutorado aprovada no Comitê de Ética em Pesquisa (CEP) da Universidade Federal do Paraná (UFPR) sob o registro CAAE 54321216.3.0000.0102.

${ }^{5}$ Pesquisa de Mestrado aprovada no Comitê de Ética em Pesquisa (CEP) da Universidade Federal do Paraná (UFPR) sob o registro CAAE 83997818.6.0000.0102.

${ }^{6}$ A Declaração de Salamanca afirma que "escolas deveriam acomodar todas as crianças independentemente de suas condições físicas, intelectuais, sociais, emocionais, linguísticas ou outras" (UNESCO, 1994). Sob a perspectiva da Declaração, o termo NEE "refere-se a todas aquelas crianças ou jovens cujas necessidades educacionais especiais se originam em função de deficiências ou dificuldades de aprendizagem"; nesse sentido, cabe à escola "encontrar formas de educar com sucesso estas crianças, incluindo aquelas que apresentam incapacidades graves" (UNESCO, 1994). A Declaração de Salamanca aponta ainda que "crianças e jovens com necessidades educacionais especiais devam ser incluídas em arranjos educacionais feitos para a maioria das crianças. Isto levou ao conceito de escola inclusiva" (UNESCO, 1994).

${ }^{7}$ Destacamos que "o conceito de vivência (perejivânie) aparece em Vygotsky designando tanto a apreensão do mundo externo pelo sujeito e sua participação nele, quanto a de seu próprio mundo interno [...]. Designa o modo pelo qual o mundo afeta-nos, tornando-se apreensível, inicialmente apenas através dos processos psicológicos geneticamente biológicos e, posteriormente, também através da medicação dos signos" (TOASSA, 2009, p. 61). O conceito de vivência evidencia, assim, a concepção monista de Vygotsky, segundo a qual a compreensão das relações implica sempre na união entre pensamento e emoção em um contexto histórico e culturalmente situado. 